GEOFIZIKA VOL. $36 \quad 2019$

DOI: $10.15233 / g f z .2019 .36 .6$

Original scientific paper

\title{
Regional analysis of wind velocity patterns in complex terrain
}

\author{
Radian Belu ${ }^{1,2}$ and Darko Koračin ${ }^{3,4}$ \\ ${ }^{1}$ Department of Electrical Engineering, Southern University and A\&M College, \\ Baton Rouge, Louisiana, USA \\ ${ }^{2}$ Faculty of Engineering, University "Lucian Blaga", Sibiu, Romania \\ ${ }^{3}$ Desert Research Institute, Reno, Nevada, USA \\ ${ }^{4}$ Physics Department, Faculty of Science, University of Split, Split, Croatia
}

Received 3 April 2019, in final form 31 May 2019

Wind energy is a weather and climate-dependent energy resource with natural spatio-temporal variabilities at time scales ranging from fraction of seconds to seasons and years, while at spatial scales it is strongly affected by the terrain and vegetation. To optimize wind energy systems and maximize the energy extraction, wind measurements on various time scales as well as wind energy forecasts are required and needed. This study focuses on spatio-temporal characteristics of the wind velocity in complex terrain, relevant to wind energy assessment, operation, and grid integration, using data collected at 11 towers ranging from 40 to $80 \mathrm{~m}$ tall over a 12-year period in complex terrain of westerncentral and northern Nevada, USA. The autocorrelation analysis, Detrended Fluctuation Analysis (DFA) and Detrended Cross-Correlation Analysis (DCCA) showed strong coherence between the wind speed and direction with slowly decreasing amplitude of the multi-day periodicity with increasing lag periods. Besides pronounced diurnal periodicity at all locations, statistical analysis and DFA also showed significant seasonal and annual periodicities, long-memory persistence with similar characteristics at all sites and towers with a relatively narrow range of the Weibull parameters. The DCCA indicates similar wind patterns at each tower, and strong correlations between measurement sites in spite of separations of about $300 \mathrm{~km}$ across the towers' setup. The northern Nevada area exhibits higher wind resource potential and higher wind persistence compared to the western-central region. Overall, the DFA and DCCA results suggest higher degree of complementarity among wind data at measurement sites compared to previous standard statistical analysis.

Keywords: wind towers, wind energy, wind resource assessment, detrended fluctuation analysis, wind regime, autocorrelation analysis, detrended cross-correlation analysis 


\section{Introduction and experiments setup}

Investments in renewable energy are justified in both environmental and economic terms. On the one hand, climate change risks claim for mitigation strategies aimed at reducing pollutant emissions and, on the other hand, energy supply is facing high uncertainty by the current or future global economic crisis, and the foreseen fossil fuel resources' depletion. Consequently, there is strong need to replace fossil fuels-based electricity generation with wind, solar, geothermal, biomass, or/and water electricity generation. Wind energy is playing a strategic role in efforts of any country for sustainable development and energy supply security. Assessment and forecasting of wind resources is of great importance for the community, especially in times of global climate change (e.g., Pryor and Barthelemie, 2010). Wind turbines and associated technologies are rapidly advancing for both large- and small-scale facilities. Due to the high spatial and temporal wind and turbulence variabilities, it is essential to understand wind patterns and evolution. To optimize wind energy systems and to maximize energy extraction, annual, monthly, daily, hourly, and even minute wind velocity probability distributions, wind velocity measurements, as well as wind energy forecasting are needed and required. Wind power intermittency and variability have also negative effects on grid power quality and wind energy economics.

From observational viewpoints, surface measurements with approximate interpolation and extrapolation algorithms are in most cases insufficient and inaccurate to determine wind properties aloft. Efficient and recommended observations include in situ measurements with towers and remote sensing using acoustic sounders and lidars. Wind is a weather- and climate-dependent energy resource, with natural spatio-temporal variability at time scales ranging from fraction of seconds to seasons and years, while being strongly affected by the terrain and vegetation. As the turbine hub heights and size of blade sizes are increasing, it is important to analyze and predict 3-D wind and turbulence structure. Accurate assessment, modeling, and forecasting of the spatial and temporal properties of the winds and turbulence, especially in complex terrain, remains the most significant challenge in wind energy production (Koračin et al., 2014a). Three main approaches to wind and wind power predictions are: physical, statistical, and computer-learning techniques. The physical approach consists of using high resolution numerical models to predict winds and wind shear in the atmospheric boundary layer relevant to wind resource assessment (e.g., Horvath et al., 2012; Smith et al., 2014). Various statistical methods are used to examine the relationships between measurements, observations and past weather forecasts to estimate most likely wind behavior in the future. The computer-learning techniques are based on AI principles to find relationships between input data and power output data (e.g., artificial neural networks, Bayesian network, and fuzzy logic). Details on various approaches to wind and wind power forecasting can be found in Koračin et al. (2014b). 
Wind velocity spatio-temporal variability can be also modeled using longmemory processes, involving not only wind velocity probability distributions, but also auto- and cross-correlation coefficients. The integration of large-scale wind power puts forward significant challenges to power system coping with inherent uncertainty of energy sources. Stochastic and fluctuating nature of wind power requires significant flexibility from power systems, bringing issues on storage, reliability, and cost. The spatio-temporal wind power correlations have significant impacts on its overall uncertainty and in turn, their impacts on the power system planning and operation (Calif and Schmidt, 2014). While temporal correlations are reflecting the power output of each wind energy system, the spatial correlations may reveal dependency among different wind energy sites. Characterizing wind variability and resource complementarity is especially challenging over complex terrain. The observational networks in complex terrain need reasonably high density of spatial sampling to adequately resolve the most important flow characteristics. Usually, slow flow fluctuations are mainly due to atmospheric dynamics and they are widely correlated spatially and temporally. Slow fluctuations in power output of near wind farms are quite correlated with wind characteristics and wind forecast models are used to optimize power dispatch. However, fast wind speed fluctuations are mainly due to meteorological mesoscale and microscale dynamics. The studies of wind velocity and wind energy correlations at wind farms over the last twenty years have yielded several important insights with relevance to grid integration, power system operation, and planning. To manage wind power variability and uncertainty, new statistical tools are being sought, developed, and utilized. The main objective of this study is to investigate statistical relationships of data from a network of tall towers in complex terrain in Nevada. In particular, the emphasis is on spatiotemporal characteristics of data from eleven towers relevant to wind power assessment in the period 2003-2014.

\section{Data analysis and methodology}

The data analyzed in this work were collected during several field campaigns, using meteorological towers operated by the Desert Research Institute, Reno, Nevada, USA. The towers were operated from September 2003 through March 2014. The objectives of these field programs were to analyze and assess the wind energy potential in this area of west-central and northern Nevada (Belu and Koračin, 2009, 2013; Koračin et al. 2009, 2014a) and evaluate high-resolution models with fixed and adaptive grid structures. This area is characterized by complex terrain in the proximity of the Sierra Nevada and Inyo Mountain ranges. The region has complex patterns of wind climate, governed by a variety of non-linear and non-hydrostatic phenomena (Horvath et al., 2012; Smith et al., 2014). The region climate is generally semiarid and vegetation is sparse. The current observational evidence of the near-surface winds and their diurnal and 

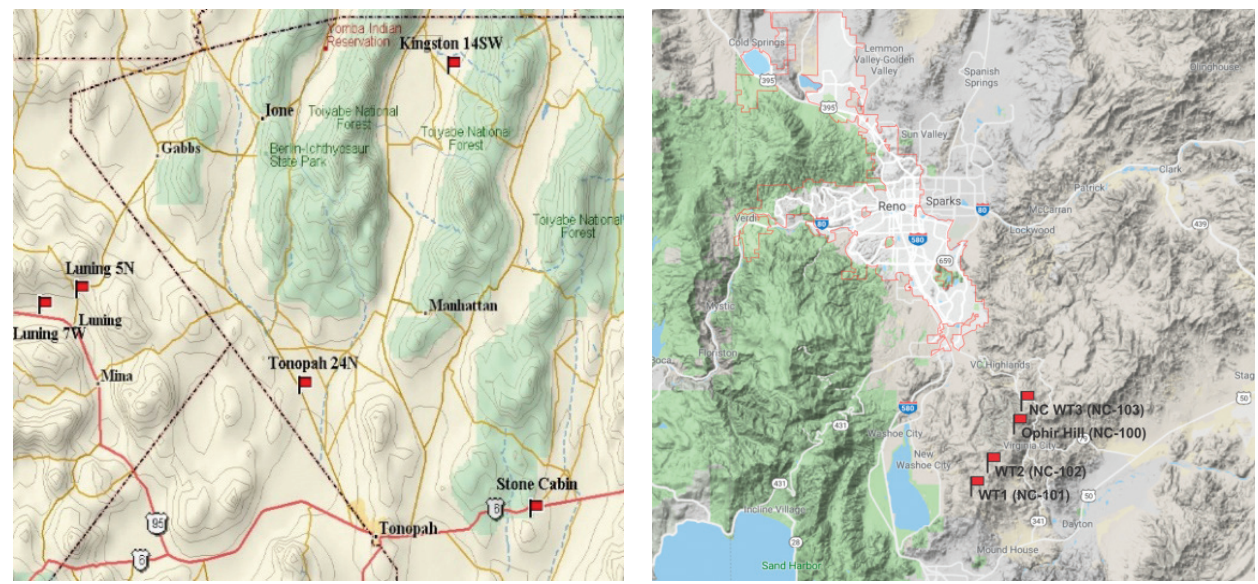

Figure 1. Topographical setup of wind tower locations: 50-m and 80-m towers near Tonopah [Belu and Koračin, 2009, 2013] (left panel) and Reno and Washoe Valley ridge areas (Wind Tower 1 (WT1), WT2, $60 \mathrm{~m}$ towers; and Ophir Hill, North Comstock (NC100), and WT3 (NC103) 40-m towers) [Koračin et al., 2014a] (right panel). See the text for details.

seasonal variability in Nevada is rather poor, except for knowledge from a sparse network of surface stations and a few field experiments.

The first experiment, consisting of four 50-m towers and one 80-m tower was run near Tonopah, located in western Nevada. Figure 1 shows the tower locations and terrain characteristics of the experimental sites. The 50-m towers were operated for a period of over four and half years from August 2003 through March 2008. The wind speed was measured with cup anemometers at the $10-\mathrm{m}, 20-\mathrm{m}$, 30-m, 40-m, and 50-m levels, while the wind directions were measured by wind vanes at the 10-m and 50-m levels.

During the second experiment, an additional 80-m tower was operated near Tonopah from February 2007 until March 2008. The wind velocity was measured by sonic anemometers with a sampling rate of $20 \mathrm{~Hz}$ at four levels: $10 \mathrm{~m}, 40 \mathrm{~m}$, and $80 \mathrm{~m}$.

The third experiment was conducted, almost continuously, in the northern region of Nevada from May 2006 until March 2014 (Belu and Koračin, 2009, 2013; Koračin et al. 2009, 2014a). The field programs included two 60-m towers (WT1-NC101, and WT2-NC102) instrumented with standard and sonic anemometers, and deployment of an acoustic sounder. The towers were located on ridges of the Virginia Hills, Nevada. The Virginia Mountains is an irregular mountain range in Washoe County, Nevada, north of Reno, extending northnorthwest to south-southeast for about $35 \mathrm{~km}$. Ophir Hill is one of the summits in Storey County, Nevada, near Virginia City, $39.3^{\circ} \mathrm{N}$ and $119.6^{\circ} \mathrm{W}$, and at the approximate elevation of 2,369 $\mathrm{m}$ above sea level. WT1 and WT2 towers were 
located 2,700 m apart with a vertical distance of $140 \mathrm{~m}$. Each tower had a downhill exposure of rolling complex terrain, with the nearby valley floor at 3,200 m to the west and $800 \mathrm{~m}$ below the summit. Instrumentation on the $60-\mathrm{m}$ towers consisted of the following: cup anemometers at $20 \mathrm{~m}, 40 \mathrm{~m}$, and $60 \mathrm{~m}$, sonic anemometers at $20 \mathrm{~m}$ and $60 \mathrm{~m}$, and wind vanes at $20 \mathrm{~m}$ and $60 \mathrm{~m}$. The fourth experiment included one 60-m tower and two 40-m towers located in the proximity of the Reno and Carson City area (see Fig. 1, right panel). Setups of instrumentation on the NC103 (WT3) tower was similar to WT1 and WT2 towers, while NC100 (Ophir Hill) had also measurements at $20 \mathrm{~m}$ and $40 \mathrm{~m}$ levels. Abbreviations NC for tower identification stand for New Comstock, where Comstock is a district in Nevada. For the full experimental settings details please see Belu and Koračin $(2009,2013)$ and Koračin et al. (2009, 2014a).

Wind energy potential assessment at a site or area requires analysis of wind characteristics, probability distributions of the measured wind speed and direction, the maximum wind speed, and the wind variability and seasonality. Before the statistical and spectral analysis of the data, a quality control of all data was performed to remove outliers and to interpolate over small data gaps that may be present. Overall, the corrected data are of sufficient quality, with less than $3 \%$ of the data removed as outliers or unacceptable data (Belu and Koračin, 2009, 2013; Koračin, 2014a). Only exception was one of the 60-m towers from the second experiment for which about 2 months of data in summer of 2012 were lost due to the equipment malfunction. Wind velocities less than $0.5 \mathrm{~ms}^{-1}$ were recorded as calm and were not included in this analysis.

\section{Wind complementarity and variability}

Wind power variability and complementarity tend to follow local wind patterns (Belu and Koračin, 2013). Variations are caused by synoptic processes and local topography. Such intermittent and fluctuating energy generation has impacts on power systems. An expectation is that co-locating wind-generated electricity can assure higher total output of the two when either one of the two sources increases and can improve the stability and reliability of the generated power, while phasing out some of the inherent variability of these energy sources. One expects similar effects, even with more constant power outputs, for renewable energy generators distributed on a larger geographical area. The variability and complementarity nature of wind speed was qualitatively noted, however, with limited number of studies attempting their quantitative aspects (Bunde and Lennartz, 2012; Aguera-Perez et al., 2013; Belu and Koračin, 2013; Calif and Schmidt, 2014; Camboin Lopez de Figueredo, 2014; Govidan, 2004; Kocak, 2009). Correlations are quantifying the similarities between two time series, or characterizing repeated patters in time series, while the correlograms are used to represent the time series relationships in visual manners. Autocorrelations indicate the structural dependence of its successive elements, being 
closely related to complementarity, variability, and persistence. The simplest method of analysing longer-term variations is the use of a moving average, computed as:

$$
\bar{U}_{N}(k)=\frac{1}{m} \sum_{i=-p}^{i=+p} v_{l+i}
$$

Here, $m=2 p+1$, the length of the moving averaging interval, $v i$ is the measured wind speed, for $l=1,2, \ldots, N$ samples, and $\bar{U}_{N}(k)$ is the computed moving average. The moving averages corresponding to an averaging period of one month were computed using the wind speed measured at each site for all measurement levels. Figure 2a shows the moving averages for all 50-m towers for the composite 2003-2008 data sets and for Ophir Hill 40-m towers, 2006-2010 composite data sets. The figure indicates seasonal variations of the wind speed at all five sites and shows a typical annual cycle with a maximum during the spring and with a minimum during the fall. It is clear that a longer measurement period is required to further confirm the seasonality. In order to investigate possible presence of an annual cycle, daily means and their autocorrelations of all composite data were computed. Figure $2 \mathrm{~b}$ shows autocorrelations of daily means for the Ophir Hill tower and for the Tonopah towers composite data sets. The presence of a deterministic component with a period of about one year is clearly visible in the daily wind speed average autocorrelation diagrams. Once again, this is in very good agreement with the periodicity found in the moving average wind speed diagrams. This is a very important fact for the wind energy conversion systems operation, development, management, and grid integration. Note that autocorrelations of the WT1 data are not included in the figure since they are similar, almost overlapping, to the Ophir Hill data.
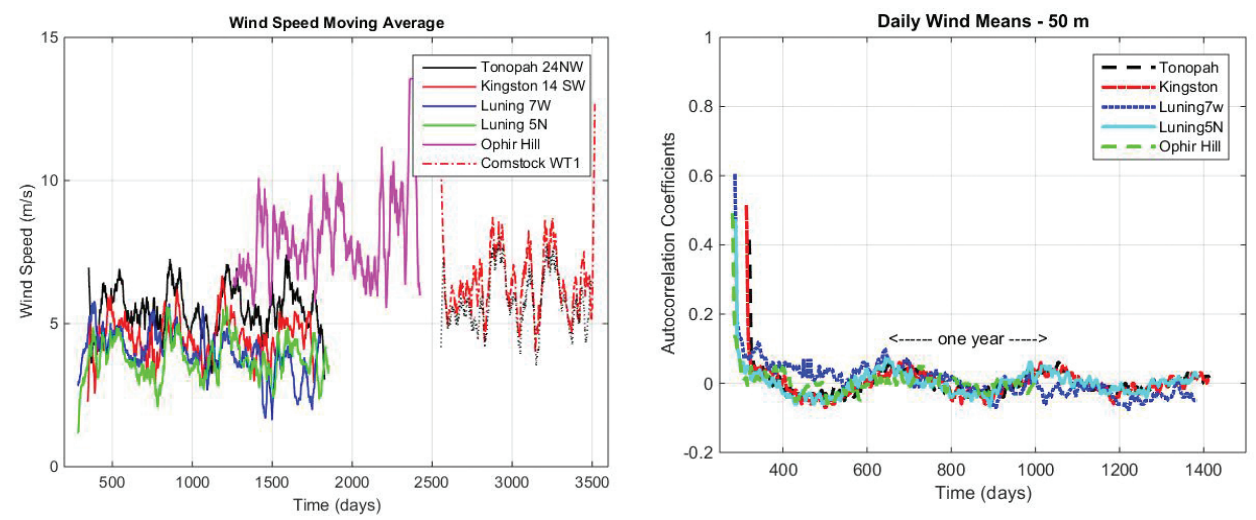

Figure 2. Wind speed moving averages for the 50-m Tonopah towers, 40-m Ophir Hill tower, and WT1 tower, composite data sets (left panel) and autocorrelations of the daily means using the Ophir Hill tower and the Tonopah towers composite data sets (right panel). 

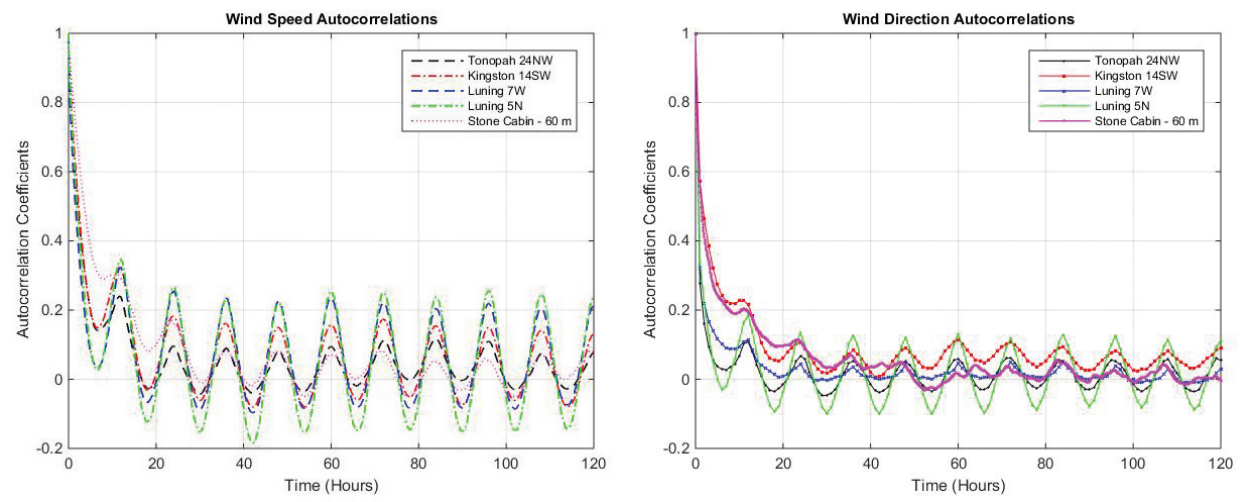

Figure 3. Autocorrelation functions for 10-min wind speed (left panel) and wind direction (right panel) for the Tonopah 2003-2008 composite data sets at the 50-m level and for the Stone Cabin data at the 60-m level.

Figure 3 shows the autocorrelation functions of the hourly wind speed and direction at the 50-m level for all four Tonopah towers and for the Stone Cabin tower at the 60-m level. The plots show similar patterns in both the wind speed and wind direction autocorrelation functions. Similar patterns were found in all time series, at all measurement levels and for all sites. It can be noted that all these autocorrelations are coincidental, and they show similar daily periodicity. Regular oscillations exist, indicating a quite well-defined periodicity of the wind speed in western Nevada in accordance with previous studies (Belu and Koračin, $2009,2013)$. A very slow decrease in the amplitude of the oscillation, as the lag time increases, indicates that the wind speed is not strictly periodic but is randomly modulated in frequency and phase (Fig. 3, left panel). This behavior is also observed in the wind direction autocorrelation functions illustrated in Fig. 3 (right panel) for the same towers.

A maintained oscillatory character of these autocorrelation functions indicates that the dominant frequencies associated with the wind speed and direction are roughly coincidental. Similar patterns were found for all levels and towers, both for wind speed and direction autocorrelations, as well as for cross-correlations, indicating that wind speed and direction signals are in phase. It can be also noted that the lag time corresponding to the maximum values of the autocorrelation functions is about 24 hours. This 24 -hour period, as the dominant in the signals, shows that this is the time interval that basically governs the changes in wind speed and wind direction. This is related to the day and night changes in local circulation patterns which roughly maintain their structure during almost five years of the analyzed time interval. All the autocorrelations show the presence of a strong diurnal sinusoidal component, which is almost constant as the lag value increases. This indicates that is derived from a deterministic period component, and that the diurnal component of the centerline is not the zero 
datum line, but is offset above the lag axis. This offset cannot be due to a zero mean (removed by the autocorrelation), suggesting the presence of another periodic component of a much lower frequency. The obvious candidate for this periodic component is an annual cycle. This is also in agreement with the presence of a spring maximum and a fall minimum in the wind speed moving average time series (see Fig. 2 for details).

\subsection{Detrended fluctuation analysis and detrended cross-correlation analysis}

To further extend the analysis, the Detrended Fluctuation Analysis (DFA) was used to quantify and compare correlations in wind velocity time series. DFA is a modified root-mean-squares (RMS) analysis using the random walk approach. In short, DFA computes the RMS error of linear fits (or higher-order polynomials and other fitting functions) over progressively larger bins (nonoverlapped "boxes, segments, or intervals" of similar size) of an integrated time series. A box (segment) contains a defined number of samples; the box size represents, therefore, the scale at which the signal is observed. The relationship between the overall RMS error and the box size is called the fluctuation function. When the fluctuation function follows a linear trend in double-log plots, the slope of this linear trend is a scaling parameter a that provides a measure for evaluating two critical properties of the data series: the presence of long-range correlations and fractal dynamics. Parameter a is related to the Hurst exponent (Koscielny-Bunde, 2006; Telesca et al., 2012) and is used as a measure of long-term memory of a time series. It relates to the autocorrelations of the time series, and the rate at which they decrease as the lag between pairs of values increases. DFA was introduced by Peng et al. (1994) for linear detrending and it was later extended to higher-order polynomials. This method is very suitable to quantify long-term correlations in non-stationary signals and has been successfully applied to physiological processes, weather records, geophysics, and financial data (Bunde and Lennartz, 2012; Kilarly and Janosi, 2005; Koscielny-Bunde et al., 2006; Marinho et al., 2013; de Oliveiera Santos et al., 2013; Sales dos Anjos et al., 2015; Suteanu, 2015; Telesca et al., 2012, 2016; Wang and Xie, 2013).

There are two major reasons why DFA is essential to properly analyze time series: first, detrending method prevents the analysis of time series to show being correlated if correlations are not present; and second, the DFA can reveal genuine correlation dependence if correlations do exist, while the conventional correlation analysis may fail. Most methods using DFA methods start with the assumption that the functional form of trend is a predominant one (KoscielnyBunde et al., 1998, 2006; Malamund et al., 2006; Peng et al., 1994; Telesca and Lapenna, 2006; Telesca, 2007; Witt and Malamund, 2013). The detrending application to original data can be either global or local. There are many situations that two or more variables are simultaneously recorded that can exhibit longrange dependence or multi-fractal nature (Podobnik and Stanley, 2008; Podobnik et al., 2009; Wang et al., 2013; Zebebded and Machado Filho, 2009). This can be 
applied to wind velocity, temperature, humidity, solar radiation, or indexes and trading volumes in financial markets (Hajian and Sadegh, 2010; Kirstoufek, 2014; Telesca et al., 2012, 2016; Vassoler and Zebende, 2013; Zebende et al., 2013; Wang et al. 2013).

In recent years the Detrended Cross-Correlation Analysis (DCCA) was proposed to investigate the long-range cross-correlations between two non-stationary time series. It is a generalization of the DFA method and is based on detrended covariance, designed to investigate power-law cross-correlations between two simultaneously recorded non-stationary time series, extensively applied in finance, climatology, geophysics, and medicine (Podobnik and Stanley, 2008; Zebende, 2011; Zebende et al., 2013). This method is also suitable to quantify long-term correlations in non-stationary signals. However, this method has been less frequently used in the wind energy studies.

The DFA method, an improvement of the classical fluctuation analysis which allows the estimation of correlation properties on large time series, is described here. Firstly, we compute the cumulative mean of the fluctuation time series or so-called 'profile' of a time series:

$$
X(n)=\sum_{i=1}^{N}\left(x_{i}-\bar{x}\right)
$$

Here, $\bar{x}$ is the time series mean. Notice that the mean subtraction is not compulsory, since it would be eliminated by later detrending. The time series is then segmented into, $N_{s}=\operatorname{int}(N / s)$, non-overlapping segments, intervals or boxes of the same size (number of the elements in the interval), $s$, the length scale. It is not critical the time series size, $N$, to be an integer of multiple scale, $s$, therefore a short part of time series may exist at the end of the time series. In order to acquire a high degree of accuracy in the estimation process, the forward procedure is then applied from the opposite end of the time series (the backward direction). Thereby, $2 N_{s}$ segments, intervals, or boxes of the same size (s) are obtained. In each box, the integrated time series is adjusted by using a least square linear regression, or a higher-order polynomial function to determine a trend. Then the local trend is subtracted to obtain the detrended fluctuation functions (Bunde and Lennartz, 2012; Kiraly and Janosi, 2005; de Oliveira Santos et al., 2012; Suteanu, 2015). Usually, the fluctuation functions for different determining polynomials used are named DFA1, DFA2, DFA3, etc. Note that the use of polynomials for detrending time series are sometimes necessary for improved capturing of the power-law behavior. It should be noted that the trend elimination in a time series depends on the DFA order. After detrending, for each segment or interval of size $s$, the forward and backward variances are determined. Linear, quadratic, cubic, or higher-order polynomials are usually employed in the fitting procedure. Then the root-mean square (RMS) fluctuation, $F(s)$, is computed: 


$$
F(s)=\sqrt{\frac{1}{2 N_{s}} \sum_{m=1}^{2 N_{s}} x_{s}^{2}}(m)
$$

Here, $x_{s}(m)$ for $1 \leq m \leq 2 N_{s}$, is the difference between the integrated (cumulative) time series and the fitted trend for a box (interval) of size, $s$. Repeating this calculation for different segments (intervals or boxes) sizes provides the relationship between the fluctuation function, $F_{D F A}(s)$, computed for each segment size as in (3) and the segment size $s$ (Marinho et al., 2013; Sales dos Anjos et al., 2015; Suteanu, 2015; Telesca et al., 2012, 2016).

Typically, $F_{D F A}(s)$ increases with $s$ according to a power law, as:

$$
F_{D F A}(s) \sim s^{\propto}
$$

In this way, one can obtain the average fluctuation $F(s)$ as a function of the box, interval or segment size $s$. A linear relationship in a double logarithmic diagram reveals a scaling factor between those magnitudes. If the points are aligned on the line slope, they represent a scaling exponent. The scaling exponent $\alpha$ is obtained as the slope of regression (least square line fitting) of $\log \left[F_{D F A}(s)\right]$ vs. $\log (s)$. The value of $\alpha=0.5$ indicates the absence of correlation (uncorrelated signals), $\alpha>0.5$ indicates persistent log-term correlations, meaning that large (small) values are more likely to be followed by large (small) values. Values $\alpha<0.5$ indicate persistent long-term anti-correlations, meaning that large values are more likely to be followed by small values and vice versa. The higher is the $\alpha$ value the stronger is the persistence (Peng et al., 1994; Telesca et al., 2012, 2016).

The DCCA procedure consists of the integration of two simultaneously recorded time series $X(i)$ and $Y(i), i=1, \ldots, N$ to produce a cumulative deviation of each time series. Then two new sequences were obtained (Horvatic et al., 2011; Sales dos Anjos et al., 2015; Telesca et al., 2012, 2016; Vassoler and Zebende, 2013; Zebende et al., 2013), where $k$ is an integer between 1 and $N$. $X$ and $Y$ are expressed as:

$$
X(k)=\sum_{i=1}^{k}\left(x_{i}-\bar{x}\right), \text { and } Y(k)=\sum_{i=1}^{k}\left(y_{i}-\bar{y}\right)
$$

Here, overbar on $x$ and $y$ denotes the average values of the time series. The two cumulative time series (5), $X(k)$ and $Y(k)$ are then divided into $N_{s}=\operatorname{int}(N / s)$, non-overlapping segments, intervals or boxes of equal length $s$, as in the DFA method. Because often the time series length, $N$, is not an integral multiple of the scale size, $s$, a short part at the end of each sequence (time series) may be left out. Then the procedure, similarly to the DFA method, is reduplicated from the opposite end of each time series, so the entire time series is included. A linear (or a higher-order polynomial) is applied in each segment in order to capture the local trend in a similar way as it was applied in the DFA procedure. The inte- 
grated series $X(k)$ and $Y(k)$ are detrended by subtracting the defined local trends $\tilde{X}_{v}$ and $\tilde{Y}_{v}$ (the fitted polynomial within each segment $l=1, \ldots, N_{s}$ ) from the data in each box. Then, the detrended covariance is computed for the forward time series, as:

$$
f^{2}(l, s)=\frac{1}{s} \sum_{i=1}^{s}\left|X[(l-1) s+i]-\tilde{X}_{l}(i)\right| \cdot\left|Y[(l-1) s+i]-\tilde{Y}_{l}(i)\right|
$$

And for the reduplicated time series, as:

$$
f^{2}(l, s)=\frac{1}{s} \sum_{i=1}^{s}\left|X[N-(l-1) s+i]-\tilde{X}_{l}(i)\right| \cdot\left|Y[N-(l-1) s+i]-\tilde{Y}_{l}(i)\right|
$$

for each interval, $l=N_{s}+1, N_{s}+2, \ldots, 2 N_{s}$. The detrended covariance fluctuation function $F_{D C C A}^{2}$ is then calculated by averaging over all intervals (boxes or segments), as:

$$
F_{D C C A}^{2}(s)=\frac{1}{2 N_{s}} \sum_{l=1}^{2 N_{s}} f^{2}(l, s)
$$

If only a time series is considered, the DCCA procedure reduces to the detrended variance used in the DFA method, as discussed above. Repeating this procedure for all segment sizes and different scales, a relationship between $F_{D C C A}(s)$ and the segment size $s$ can be determined. If the two series are powerlaw correlated, then $\lambda$ (the cross-correlation scaling exponent) is determined from the linear regression of $F_{D C C A}(s) \sim s^{\lambda}$, with the same interpretation as $\alpha$, the DFA exponent. If $\lambda>0.5$, the cross-correlations between the two time series are persistent (positive), meaning an increase (a decrease) in one time series is likely to be followed by an increase (a decrease) in the other time series. If $\lambda<0.5$, the cross-correlations between the two time series are anti-persistent, meaning aincrease (a decrease) in one time series is likely to be followed by a decrease (an increase) in the other time series. When $\lambda=0.5$, the two time series are not cross-correlated. In order to further quantify the level of cross-correlation, the DCCA cross-correlation coefficient was computed. The DCCA cross-correlation coefficient, $\rho_{D C C A}$, for each time scale is defined as the ratio between the detrended covariance and the product of detrended variance function of each time series:

$$
\rho_{D C C A}=\frac{F_{D C C A}^{2}\left(x_{i}, y_{i}\right)}{F_{D F A}\left(x_{i}\right) \cdot F_{D F A}\left(y_{i}\right)}
$$

The $\rho_{D C C A}$ values are between -1 and 1 and a value of $\rho_{D C C A}=0$ means that no correlations are present. The DCAA cross-correlation coefficient has the same 
interpretation as the conventional one. The above relationship leads to a new scale for cross-correlation in the time series analysis. For a finite time series, because of the size effect, even if cross-correlations are not present, $\rho_{D C C A}$ has presumably some small nonzero value. Therefore, the DCCA cross-correlation coefficient serves only as an indicator of the presence of cross-correlations. It is worth to note that an important advantage of the DCCA cross-correlation coefficient is that it can be used to quantify the cross-correlation level between two different time series, but synchronous at various box (interval) scales $s$ (Kristoufek, 2014; Wang and Xie, 2013; Zebende, 2011).

\section{Results and discussion}

Assessment and analysis of the wind energy potential at a particular site involve analyzing characteristics and the distributions of the measured wind speed and direction. Of equal importance are also the wind variability and seasonality, such as diurnal or season variations of the wind speeds. Wind characteristics were usually studied by using various probability distribution functions of the observed wind velocities. The most common probability distribution function used in wind energy is the Weibull probability distribution (e.g., Belu and Koračin, 2009, 2013; Koračin et al., 2014b, among others).

To understand the diurnal, seasonal and annual variations of the wind speeds and direction, a comprehensive statistical analysis was performed. This analysis involves autocorrelation and cross-correlations calculations, detrended fluctuation analysis, and detrended cross-correlation analysis of the 10-min, hourly, and daily composite data sets (time series) for each tower, and observation periods. Several studies (e.g., Govindan and Kantz, 2004; Kocak, 2009; Belu and Koračin, 2013) revealed that the wind speed time series are showing self-similarity properties, persistence or, more generally, fractal behavior demonstrated in a power law scaling. However, high frequency sampled records are complicated by small scale effects resulted from topography and atmospheric variability, usually failing to capture memory effects of large-scale atmospheric circulations. It appears that hourly and daily wind speed variations, and longer wind velocity records, with time scales up to hundreds of days, may reveal long-range correlations and patterns in observed wind speed time series. In order to get more insight in the complementarity and variability of the wind energy resources in the study areas, autocorrelations, cross-correlations, DFA variance, DCCA covariance, and DCCA cross-correlation coefficients were computed for all wind velocity time series and for all available combinations of all tower data time series.

The results of the DFA analysis of wind time series for the experimental sites are shown in Fig. 4. After data quality control, hourly averages of the wind velocity time series were calculated for all towers and all measurement levels. In the DFA method, the trend removal is of critical importance and depends on the used 

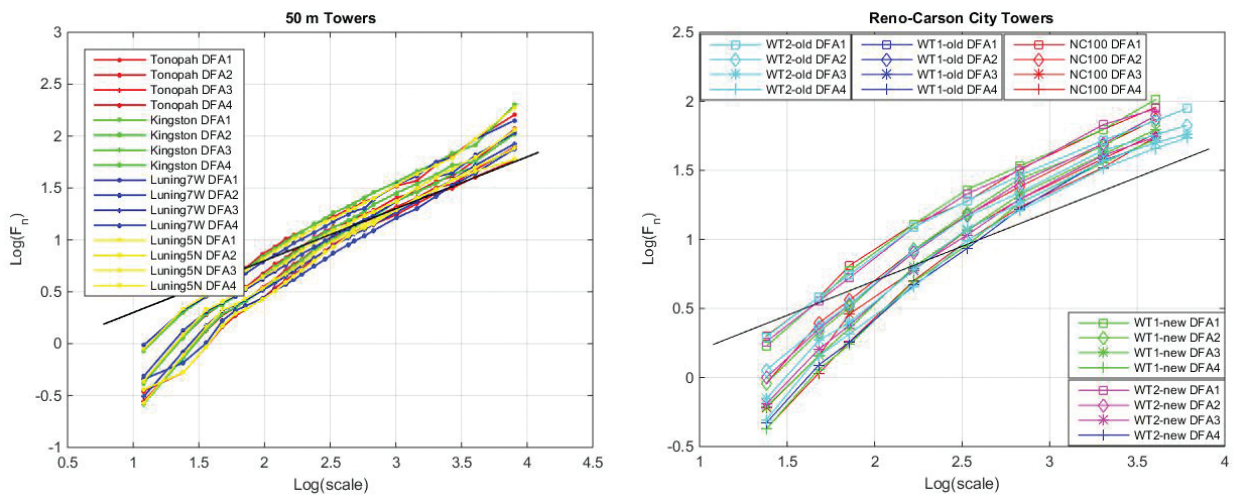

Figure 4. DFA results for the detrending polynomials of order 1, 2, 3, and 4 (DF1, DF2, DF3 and DF4) of the normalized average hourly wind speed for the Tonopah composite data sets (left panel) and the Reno-Carson City composite data sets (right panel). The 0.5 slope line is shown in each panel.

fitting procedure in the boxes or intervals. In the current analysis, linear and higher-order polynomials for each composite date sets (the time series for each site or tower and each level) were calculated and labeled as DFA1, DFA2, DFA3, and DFA4. Similarly, the DCCA method was used. Although there are quite small differences between the DFA slopes, as seen in Fig. 4, it is necessary to determine which DFA is considered here. These graphs and the ones for other towers show that the regression line slope and shape are practically the same for each of all linear and higher-order polynomial fits, suggesting that the linear fit can be used in the present analysis.

As can be seen in Fig. 4., the graphs are very similar, regardless the linear and higher-order polynomials used in detrending, i.e., the shape and slope parameters are practically the same for the linear regression and higher-order polynomials. Small differences between linear and higher order DFA may be attributed to increased fluctuations for larger scales, $s$, rather than for some external linear trends. Scaling exponents were estimated, as mentioned before, by linear regression of the log-log fluctuation curve. However, this can lead to spurious results when there is more than one scaling exponent, as in the case of crossover phenomena. One of the reasons for the application of the DFA technique is the possibility of revealing the crossover phenomenon that is distinguished by the short-range from the long-range scaling exponent. The crossover corresponds to a transition from non-persistence to persistence in a time series. In the cases of multiple scaling exponents, extracting of the global mean can be misleading. Crossover usually arises due to changes in correlation properties of the time series at different spatial or temporal scales. Recent studies have suggested comparing the results using the original and randomized shuffled data to assure higher accuracy (Kristoufek, 2013; Wang et al., 2013; Zebende, 2011; Zebende et al., 2013). Similar properties between the original and reshuffled 
wind speed data are apparent, with stronger persistence and the higher scaling exponent values. Further studies are needed to clarify these aspects and the crossover phenomena in the wind velocity time series.

A summary of power law index and statistical descriptors, the unitless shape, $k$, and the scale, $c$ of the Weibull probability distribution for all towers and for the wind velocity composite data sets (multi-annual time series), is given in Tab. 1. For details about general properties of the Weibull probability distribution see e.g., Wilks (2006) and for its applications to wind energy assessment and analysis see e.g., Belu and Koračin $(2009,2013,2015)$ or elsewhere in the literature. Values of the DFA scaling exponents, computed for all our time series are higher than 0.65 , most of them being 0.70 or higher showing strong autocorrelations and significant persistence into the wind patterns for each location. The values of the DFA scaling exponents included in Table 1 are the average values obtained by applying linear and higher-order polynomial fits, to remove the trends in our DFA analysis. However, the DFA scaling exponents, resulting from various polynomial fits, were quite similar regardless the polynomial fit order. Table 1 also includes the multi-annual values of the shape, $k$ and scale, $c$, Weibull parameters at 40-m, 50-m and 60-m levels, respectively. The values of these parameters are showing a good wind energy potential for all studied areas. The Weibull distribution $\left(f_{W B}\right)$ is well accepted and the most commonly used in wind data analysis (see e.g., Wilks, 2006), and is given by:

$$
f_{W B}=k \frac{v^{k-1}}{c^{k}} \exp \left(-\left(\frac{v}{c}\right)^{k}\right)
$$

The Weibull distribution is a function of two parameters: the shape parameter, $k$, and the scale factor, $c$, defining the curve shape or steepness and the mean value, and $v$ is the mean wind speed in $\mathrm{ms}^{-1}$.

Table 1. Tower identification, measurement interval, measurement level, DFA variance values, multiannual $k$, and $c$ Weibull parameters for each tower wind speed composite data sets.

\begin{tabular}{lccccc}
\hline Tower & $\begin{array}{c}\text { Measurement } \\
\text { interval }\end{array}$ & $\begin{array}{c}\text { Measurement } \\
\text { level }(\mathrm{m})\end{array}$ & $\begin{array}{c}\text { DFA } \\
\text { variance }\end{array}$ & $k$ & $c\left(\mathrm{~ms}^{-1}\right)$ \\
\hline Tonopah 24NW & $11 / 2003-03 / 2008$ & 50 & 0.713 & 1.703 & 6.04 \\
Kingston 14SW & $12 / 2003-12 / 2007$ & 50 & 0.705 & 1.415 & 4.82 \\
Luning 7W & $09 / 2003-03 / 2008$ & 50 & 0.716 & 1.346 & 4.39 \\
Luning 5N & $09 / 2003-03 / 2008$ & 50 & 0.746 & 1.335 & 3.99 \\
Stone Cabin & $04 / 2007-03 / 2008$ & 60 & 0.885 & 1.667 & 5.92 \\
Ophir Hill & $06 / 2006-03 / 2009$ & 40 & 0.657 & 1.745 & 7.72 \\
Comstock WT1 & $04 / 2009-04 / 2012$ & 60 & 0.695 & 1.561 & 6.94 \\
Comstock WT2 & $04 / 2009-12 / 2011$ & 60 & 0.691 & 1.578 & 6.10 \\
Comstock WT3 & $04 / 2009-11 / 2009$ & 30 & 0.693 & 1.540 & 4.88 \\
Comstock WT1 & $10 / 2012-02 / 2014$ & 60 & 0.663 & 1.561 & 6.18 \\
Comstock WT2 & $10 / 2012-02 / 2014$ & 60 & 0.703 & 1.642 & 5.35 \\
\hline
\end{tabular}



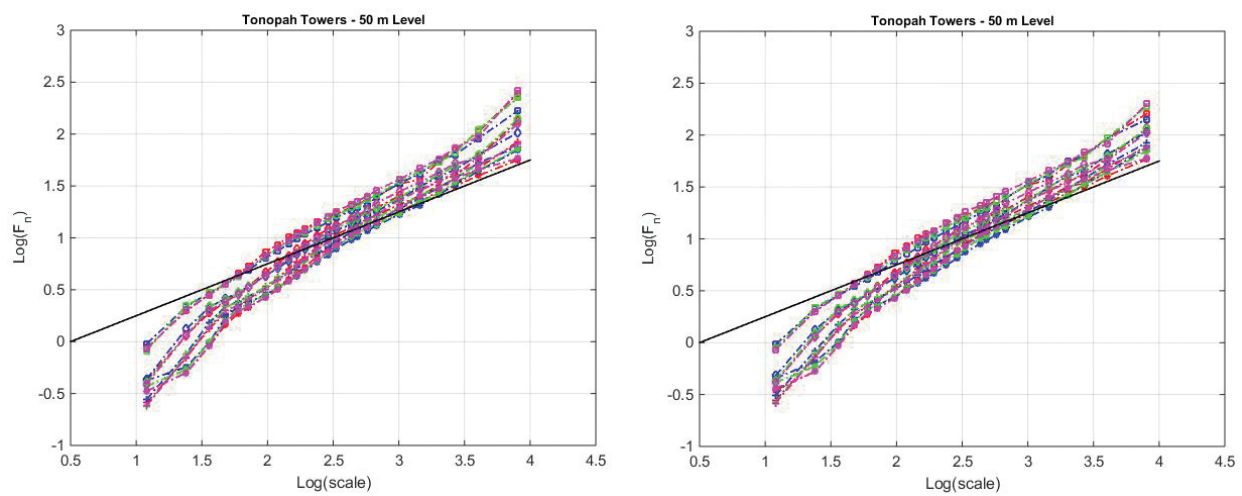

Figure 5. Scaling behavior for the 10-min measured: wind speed (left panel); and the maximum wind speed for the Tonopah 50-m towers using composite data sets (2003-2008) (right panel). The 0.5 slope line is shown in each panel.

The DFA and DCCA procedures were applied to original 10-min wind velocity time series (as in Fig. 5) and to the hourly wind speed time series (as in Fig. 4) in order to get more insight in the wind characteristics in the study areas. The main result shown in Fig. 5 (original wind speed time series) is that all graphs for the data sets at each tower present similar behavior and shapes for the wind speed and the maximum wind speed, hardly being distinguished from each other. The crossover point, the separation between the two scaling regions in the wind time series by the 0.5 slope line on the graphs, as determined in Fig. 5 , is found to be in the range between 2.0 and 3.0. Wind speeds are showing significant persistence and long-term correlation properties $(\alpha>0.5)$ for all Tonopah towers composite data sets (see Tab. 2 for details). Values of the scaling exponents are around 0.7 or higher for all towers and all data sets, showing significant persistence in the wind regime for the study areas.

The results for the Reno-Carson region (western Nevada) show similar patterns as for the Tonopah area. However, this area exhibits higher potential for wind energy with higher persistence, although these data sets are shorter than the Tonopah towers data. The similar results found for the DFA analysis of maximum wind speed for all the data sets also demonstrate a high degree of

Table 2. DCCA cross-correlation coefficients $\left(\rho_{D C C A}\right)$, for the Tonopah 50-m towers composite data sets (at the 50-m level).

\begin{tabular}{lcccc}
\hline Towers & Tonopah 24NW & Kingston 14SW & Luning 7W & Luning 5N \\
\hline Tonopah 24NW & 1.000 & 0.807 & 0.723 & 0.831 \\
Kingston 14SW & 0.807 & 1.000 & 0.432 & 0.535 \\
Luning 7W & 0.723 & 0.432 & 1.000 & 0.958 \\
Luning 5 N & 0.831 & 0.535 & 0.958 & 1.000 \\
\hline
\end{tabular}


consistence in the wind behavior in the studied areas. In order to get more insight on the complementarity and variability of the wind energy resources in the study areas, besides the autocorrelations, computations included DFA variances, DCCA covariances, and DCCA cross-correlation coefficients for all available time series and for all possible tower combinations.

The long-term cross-correlation DCCA results for the data collected during Tonopah experiment show that the DCCA cross-correlation coefficients are around 0.5 or higher, suggesting similar wind patterns, regardless the tower locations, altitudes, and topography. Table 2 summarizes the DCCA analysis and shows that the DCCA cross-correlation coefficients have only positive values at any scales, with average values ranging from 0.43 to 0.96 . These positive values of the DCCA cross-correlation coefficients indicate that the wind velocity time series have high probability of being followed by similar wind energy patterns (higher persistence), a valuable result from the wind energy development and operation point of view. These positive values of the DCCA cross-correlation coefficients also show a high degree of wind correlations among measurement sites.

\section{Conclusions and future work}

An analysis was presented on long-term correlations of wind speed time series recorded at several wind tower sites in Nevada between 2003 and 2014. All recorded wind velocity time series are characterized by long-term autocorrelations and a persistent long-memory behavior. This property is also present for annual sliding windows, along the entire recorded period for each time series studied, however, with different exponent values. Similar diurnal and seasonal periodicity was observed in the autocorrelations for all wind time series. Statistical cross-correlation tests were performed in order to quantify whether the cross-correlations are significant or not.

A procedure to quantify whether cross-correlations are significant or not was as follows: firstly, the values of correlation coefficients were calculated using the DFA and DCCA methods which have theoretical advantages in results compared to standard statistical tests; secondly, critical values were generated to test whether cross-correlations are genuine or not using a random number surrogate and a shuffled data surrogate; and thirdly, the range of correlation coefficients was determined within which the cross-correlations can be considered statistically significant. The cross-correlations coefficients, computed using both regular statistical methods and detrended fluctuation analysis, indicate that wind data are auto- and cross-correlated.

These results suggest that the long-term correlations exhibit the same behavior across the studied areas in Nevada in spite of separation of about $300 \mathrm{~km}$ across the towers network. In conclusion, the calculated hourly and daily wind speed time series of the data recorded between 2003 and 2014 in the studied 
areas in Nevada display long-term correlations with two distinct scaling regions into the daily and seasonal frequencies. For temporal scales longer than one day the scaling exponent is higher than 0.5 meaning that wind time series are persistent, a very important result for wind energy development, grid integration, and exploitation. Future work is planned to compute power spectra of all available data sets and compare with the DFA and DCCA results in order to get additional insight in the complementarity, variability, and the effects of complex terrain and synoptic processes relevant to the wind energy resources.

Acknowledgements - We acknowledge support from the DOE-NREL, grant\# (NDO 5-443101), and DOE Award \#: NAX-9-66014-02 (DE-AC36-08G028308); DRI \# 001523-008. DK was partially supported under the project STIM - REI, Contract Number: KK.01.1.1.01.0003, a project funded by the European Union through the European Regional Development Fund - the Operational Programme Competitiveness and Cohesion 2014-2020 (KK.01.1.1.01).

We thank Mr. Greg McCurdy of the Desert Research Institute, Reno, Nevada for helping with data acquisition.

\section{References}

Aguera-Perez, A., Palomares-Salas, J. C., Gonzalez de la Rosa, J. J. and Moreno-Munoz, A. (2013): Spatial persistence in wind analysis, J. Wind Eng. Ind. Aerodyn., 119, 48-52, DOI: 10.1016/j. jweia.2013.05.011.

Belu, R. G. and Koračin, D. (2009): Wind characteristics and wind energy potential in Western Nevada, Renew. Energ., 34, 2246-2251, DOI: 10.1016/j.renene.2009.02.024.

Belu R. G. and Koračin, D. (2013): Statistical and spectral analysis of wind characteristics relevant to wind energy assessment using tower measurements in complex terrain, J. Wind Energ. (739162), DOI: 10.1155/2013/739162.

Belu R. G. and Koračin, D. (2015): Wind energy analysis and assessment, Adv. Energ Res., 20(1), $1-55$.

Bunde, A. and Lennartz, S. (2012): Long-term correlations in earth sciences, Acta Geophys., 60, 562-588, DOI: 10.2478/s11600-012-0034-8.

Calif, R. and Schmitt, F. G. (2014): Multiscaling and joint multiscaling description of the atmospheric wind speed and the aggregate power output from a wind farm, Nonlinear Proc. Geoph., 21, 379-392, DOI: 10.5194/npg-21-379-2014.

Camboim Lopes de Figueredo, B., Rocha Moreiro, G., Stosic, B. and Stosic, T. (2014): Multifractal analysis of hourly wind speed records, in Petrolina, northeast Brazil, Rev. Bras. Biom., 32, 599608.

Govindan, R. B. and Kantz, H. (2004): Long-term correlations and multifractality in surface wind speed, Europhys. Lett., 68, 184-190, DOI: 10.1209/epl/i2004-10188-3.

Hajian, S. and Sadegh, M. (2010): Multifractal detrended cross-correlation analysis of sunspot numbers and river flow fluctuations, Physica A, 389, 4942-4957, DOI: 10.1016/j.physa.2010.06.025.

Horvatic, D., Stanley, H. E. and Podobik, B. (2011): Detrended cross-correlation analysis for nonstationary time series with periodic trends, Europhys. Lett., 94, 18007, DOI: 10.1209/02955075/94/18007.

Horvath, K., Koračin, D., Vellore, R., Jiang, J. and Belu, R. (2012): Sub-kilometer dynamical downscaling of near-surface winds in complex terrain using WRF and MM5 mesoscale models, $J$. Geophys. Res. - Atmospheres, 117, D11111, DOI: 10.1029/2012JD017432.

Kocak, K. (2009): Examination of persistence properties of wind speed records using detrended fluctuation analysis, Energy, 34, 1980-1985, DOI: 10.1016/j.energy.2009.08.006. 
Kiraly, A. and Janosi, I. M. (2005): Detrended fluctuation analysis of daily temperature records: Geographic dependence over Australia, Meteor. Atmos. Phys., 88, 119-128, DOI: 10.1007/s00703004-0078-7.

Koračin, D., Reinhardt, R., McCurdy, G., Liddle, M., McCord, T., Vellore, R., Minor, T., Lyles, B., Miller, D. and Ronchetti, L. (2009): Wind energy assessment study for Nevada - Tall tower deployment (Stone Cabin), Technical report submitted to DOE-NREL, No. NREL/SR-550-47085, available from: http://www.nrel.gov/docs/fy10osti/47085.pdf

Koračin, D., Kaplan, M., Smith, C., McCurdy, G., Wolf, A., Belu, R., McCord, T., King, K. and Horvath, K. (2014a): Tall tower wind energy monitoring and numerical model validation in Northern Nevada, Technical report submitted to DOE-NREL, No. NAX-9-66014-02 (DE-AC36-08G028308); DRI \# 001523-00, available from: http://www.nrel.gov/docs, DOI: 10.2172/1225900.

Koračin, D., Belu, R., Canadillas, B., Horvath, K., Vellore, R., Smith, C., Jiang, J. and McCord, T. (2014b): A review of challenges in assessment and forecasting of wind energy resources, Croat. Met. J., 47, 13-33.

Koscielny-Bunde, E., Bunde, A., Havlin, S., Roman, H. E., Goldreich, Y. and Schellnhuber, H. J. (1998): Indication of universal persistence law governing atmospheric variability, Phys. Rev. Letters, 81, 729-732, DOI: 10.1103/PhysRevLett.81.729.

Koscielny-Bunde, E., Kantelhardt, J. W., Braun, P., Bunde, A. and Havlin, S. (2006): Long-term persistence and multifractality of river runoff records: Detrended fluctuation studies, J. Hydrol., 322, 120-137, DOI: 10.1016/j.jhydrol.2005.03.004.

Kristoufek, L. (2014): Measuring correlations between non-stationary time series with DCCA coefficient, Physica A, 402, 291-298, DOI: 10.1016/j.physa.2014.01.058.

Malamud, B. D. and Turcotte, D. L. (2006): The applicability of power-law frequency statistics to floods, J. Hydrology, 322, 168-10, DOI: 10.1016/j.jhydrol.2005.02.032.

Marinho, E. B. S., Sousa, A. M. Y. R. and Andrade, R. F. S. (2013): Using detrended cross-correlation analysis in geophysical data, Physica A, 392, 2195-2201, DOI: 10.1016/j.physa.2012.12.038.

de Oliveira Santos, M., Stosic, T. and Stosic, B. (2012): Long-term correlations in hourly wind speed records in Pernambuco, Brazil, Physica A, 391, 1546-1552, DOI: 10.1016/j.physa.2011.08.041.

Peng, C. K., Buldyrev, S. V., Havlin, S, Simons, M, Stanley, H. E. and Goldberger, A. L. (1994): Mosaic organization of DNA nucleotides, Phys. Rev. E, 49, 1685-1689, DOI: 10.1103/physreve.49.1685.

Podobnik, B. and Stanley, H. E. (2008): Detrended cross-correlation analysis: A new method for analyzing two non-stationary time series, Phys. Rev. Lett., 100, 084102, DOI: 10.1103/PhysRevLett.100.084102.

Podobnik, B., Horvatic, D., Petersen, M. A. and Stanley, H. E. (2009): Cross-correlation between volume change and price change, Proc. Natl. Acad. Sci., 106, 22079-22084, DOI: 10.1073/ pnas.0911983106.

Pryor, S. C. and Barthelmie, R. J. (2010): Climate change impacts on wind energy: A review, Renew. Sustain. Energy Rev., 14, 430-437, DOI: 10.1007/s10584-018-2265-4.

Sales dos Anjos, P., Alves da Silva, A. S. and Stosic, B. (2015): Long-term correlations and crosscorrelations in wind speed and solar radiation temporal time series form Fernando da Noronha Island, Brazil, Physica A, 424, 90-96, DOI: 10.1016/j.physa.2015.01.003.

Smith, C. M., Koračin, D. and Horvath, K. (2014): Day-ahead predictability of complex terrain flows for wind resource production: a case study of the Washoe Zephyr, Weather Forecast., 29, 13431355, DOI: 10.1175/WAF-D-14-00021.1.

Suteanu, C. (2015): A methodology for the time-scale-sensitive evaluation of wind speed and direction variability, Energy Procedia, 76, 200-206, DOI: 10.1016/j.egypro.2015.07.898.

Telesca, L. and Lapenna, V. (2006): Measuring multifractality in seismic sequences, Tectonophysics, 423, 115-123, DOI: 10.1016/j.tecto.2006.03.023.

Telesca, L. (2007): Cycles, scaling and crossover phenomena in length of the day (LOD) time series, Physica A, 379, 459-464, DOI: 10.1016/j.physa.2007.02.064. 
Telesca, L., Pierini, J. O. and Scina, B. (2012): Investigating the temporal variations of the scaling behavior in rainfall data measured in central Argentina by means of detrended fluctuation analysis, Physica A, 391, 1553-1562, DOI: 10.1016/j.physa.2011.08.042.

Telesca, L., Lovallo, M. and Kanevski, M. (2016): Power spectrum and multifractal fluctuation analysis of high-frequency wind measurements in mountainous regions, Appl. Energy, 162, 10521061, DOI: 10.1016/j.apenergy.2015.10.187.

Vassoler, R. T. and Zebende, G. E. (2013): DCCA cross-correlation coefficient apply in time series of air temperature and air relative humidity, Physica A, 392, 1756-1761. DOI: 10.1016/j.physa.2011.12.015.

Wang, G. J. Xie, C., Chen, Y. J. and Chen, S. (2013): Statistical properties of the foreign exchange network at different time scales: evidence from detrended cross-correlation coefficient and minimum spanning tree, Entropy, 15, 1643-1662. DOI: 10.3390/e15051643.

Wang, G. J. and Xie, C. (2013): Cross-correlations between CSI 300 spot and futures markets, Nonlinear Dyn., 73, 1687-1696. DOI: 10.1007/s11071-013-0895-7.

Wilks, D. S. (2006): Statistical methods in the atmospheric sciences, International Geophysics Series, 59. Academic Press.

Witt, A. and Malamud, B. D. (2013): Quantification of long-range persistence in geophysical time series: conventional and benchmark-based improvement techniques, Surv. Geophys., 34, 541-651, DOI: $10.1007 / \mathrm{s} 10712-012-9217-8$.

Zebende, G. F. and Machado Filho, A. (2009): Cross-correlation between time series of vehicles and passengers, Physica A, 388, 4863-4866. DOI: 10.1016/j.physa.2009.07.046.

Zebende, G. F. (2011): DCCA cross-correlation coefficient: Quantifying level of cross-correlation, Physica A, 390, 614-618. DOI: 10.1016/j.physa.2010.10.022.

Zebende, G. F., da Silva, M. F. and Machado Filho, A. (2013): DCCA cross-correlation differentiation: Theoretical and practical approaches, Physica A, 392, 1756-1761. DOI: 10.1016/j.physa.2013.01.011.

\title{
SAŽETAK
}

\section{Regionalna analiza obrazaca brzine vjetra u složenom terenu}

\author{
Radian Belu i Darko Koračin
}

Energija vjetra je energetski resurs ovisan o vremenu i klimi s prirodnim prostornovremenskim promjenjivostima koje u vremenskim razmjerima idu od sekundi do sezona i godina, dok su na prostornim razmjerima promjenjivosti snažno uvjetovane složenošću terena i vegetacije. Kako bi se optimizirali sustavi energije vjetra i maksimizirala ekstrakcija energije, potrebna su mjerenja vjetra u različitim vremenskim razmacima, kao i prognoze energije vjetra. Ova studija se fokusira na prostorno-vremenske karakteristike brzine vjetra $u$ složenom terenu, relevantne za procjenu energije vjetra $i$ integraciju $u$ elektrodistribucijske mreže, koristeći podatke prikupljene na 11 tornjeva s rasponima visina od 40 do $80 \mathrm{~m}$ tijekom 12-godišnjeg razdoblja u složenoj topografiji zapadnosredišnje i sjeverne Nevade, SAD. Autokorelacijska analiza, analiza poremećaja fluktuacija (DFA) i višestruka korelacijska analiza (DCCA) pokazale su snažnu koherenciju između brzine i smjera vjetra sa sporo opadajućom amplitudom višednevne periodičnosti s povećanjem razdoblja pomaka. Osim izražene dnevne periodičnosti na svim lokacijama, spektralna analiza i DFA također su pokazale značajne sezonske i godišnje periodičnosti, postojanost dugog pamćenja sa sličnim karakteristikama na svim mjestima i tornjevima 
s relativno uskim rasponom Weibullovih parametara. DCCA ukazuje na slične uzorke vjetra na svakom tornju i jake korelacije između mjernih mjesta unatoč udaljenostima između tornjeva čak do $300 \mathrm{~km}$. Područje sjeverne Nevade pokazuje veći potencijal vjetra i veću postojanost vjetra u usporedbi sa zapadno-središnjom regijom. Sveukupno, rezultati DFA i DCCA ukazuju na veći stupanj komplementarnosti među podacima o vjetru na različitim mjestima u usporedbi s prethodnim standardnim statističkim analizama.

Ključne riječi: vjetrovni tornjevi, energija vjetra, procjena vjetrovnih resursa, analiza fluktuacija bez trendova, vjetrovni režim, autokorelaciona analiza, analiza unakrsnih korelacija bez trendova

Corresponding author's address: Dr. Darko Koračin, Physics Department, Faculty of Science, University of Split, Ruđera Boškovića 33, HR-21000 Split, Croatia; e-mail: dkoracin@pmfst.hr 